\title{
Recreational specialization and ecologically responsible behaviour of Chinese birdwatchers in Hong Kong
}

\section{Lewis T.O. Cheung*, Alex Y.H. Lo, Lincoln Fok}

*corresponding author

Postal address: Department of Social Sciences, The Education University of Hong Kong, 10 Lo Ping Road, Tai Po, New Territories, Hong Kong

Email: 1tocheung@eduhk.hk

\section{Citation:}

Cheung, L.T.O., Lo, A.Y.H. \& Fok, L. (2016). Recreational specialization and ecologically responsible behaviour of Chinese birdwatchers in Hong Kong. Journal of Sustainable Tourism. DOI: 10.1080/09669582.2016.1251445

\footnotetext{
Abstract

Birdwatching is a popular nature-based recreational activity that has millions of participants worldwide. Hong Kong is an important birdwatching destination in Southeast Asia, and the number of birdwatchers visiting Hong Kong has steadily increased in recent decades. This study investigated the influences of recreational specialization on the proenvironmental attitudes and ecologically responsible behaviour of Chinese birdwatchers. Questionnaire surveys and interviews were conducted in Hong Kong, and 387 completed questionnaires were collected. The results of structural equation modelling indicate a direct positive association between the birdwatchers' specialization and pro-
} 
environmental attitudes and an indirect positive association between their specialization and ecologically responsible behaviour. These findings suggest that understanding birdwatchers' specialization is essential for predicting birdwatchers' behaviour when visiting ecologically sensitive destinations. Birdwatcher specialization levels could be used to formulate visitor management strategies at birdwatching sites and to mitigate visitor impacts on avian species.

Keywords: wildlife; recreational specialization; ecologically responsible behaviour; proenvironmental attitudes; China; Hong Kong

\section{Introduction}

Birdwatching is a niche pursuit among nature-based recreational activities and the number of birdwatchers has rapidly increased in recent decades (Ma, Cheng, Wang, \& Fu, 2013). Birdwatching has long been popular in several developed countries, particularly the USA and the UK (Kronenberg, 2014). Birdwatchers are considered a desirable nature-based tourism niche because they are willing to pay high travel costs to participate in birdwatching activities (Cheung \& Jim, 2014; Steven, Morrison, \& Castley, 2015). Their visits to birdwatching destinations generate considerable tourism revenues and provide significant financial support for protected areas endowed with high species diversity and endemism (Hill, Cable, \& Scott, 2010; Hvenegaard, Butler, \& Krystofiak, 1989). The popularity of birds has extended the practice of birdwatching from a localized activity into one that influences the international travel decisions of some tourists (Steven et al., 2015). 
However, management actions are required to reduce the ecological impacts of intensive tourism (Giglio, Luiz, \& Schiavetti, 2015). Like other forms of ecotourism, birdwatching activities may negatively impact wildlife and their habitats. Previous studies have reported that wildlife recreationists can influence wildlife behaviour by increasing wildlife shyness and wariness, with wildlife decreasing their distance to cover (Douglas, 1971; Knight \& Temple, 1986; Marzluff, 1988). In addition, Knight and Temple (1986) reported that birds can become more aggressive towards humans and may alter their nest placements based on their prior experiences with humans (Marzluff, 1988). Efforts are needed to promote wildlife-friendly birdwatching practices, particularly in developing countries such as China, where ecological awareness among the populace remains low (Cheung, Fok, Tsang, Fang, \& Tsang, 2015; Vicente-Molina, Fernández-Sáinz, \& Izagirre-Olaizola, 2013), and the tools available to managers of protected areas for shaping birdwatching practices are not well developed. This study addresses the need for knowledge that might help change birdwatcher behaviour in the field.

Previous studies have investigated birdwatchers by collecting and analysing their demographic characteristics and characterizing their activities along a recreational specialization spectrum (Hvenegaard, 2002; Maple, Eagles, \& Rolfe, 2010; McFarlane, 1994, 1996). Some of these studies have investigated how specialization can be used to predict motivations and conservation behaviour. Scott and Thigpen (2003) focused on how specialization is related to destination preferences. More recently, studies have investigated both the positive and negative impacts of birdwatching on avian communities and biological conservation (Burger, Jeitner, Clark, \& Niles, 2004; 
Kronenberg, 2014; Sekercioglu, 2002). However, all of these previous studies were conducted in Western countries, such as the United States, the United Kingdom, Canada, Australia and various European countries. Despite the increase in outbound Chinese tourism, few studies on birdwatchers have been conducted in Asia, although a number of Chinese scholars have investigated the growing trends and demographic characteristics of birdwatchers based on small-scale surveys. For example, Li, En, and Ling (2009) reported the demographic characteristics of birdwatchers in Beijing, and Ma et al. (2013) reported that a large expansion of birdwatching has occurred in mainland China over the past decade and that birdwatching organizations have been established in most provinces. Cheng, Wang, He and Ma (2013) reported that there are more than 20,000 active birdwatchers in mainland China.

However, there is a lack of knowledge of the underlying influences of ecologically responsible behaviour of birdwatchers. Previous studies reported that increased specialization among nature-based recreationists was a potential influencing factor as it is often associated with relevant ecological knowledge, it might be positively associated with ecologically responsible behaviour at nature-based destinations (Dearden, Bennett, \& Rollins, 2007; Ong \& Musa, 2012). We explored this possibility by introducing the concept of recreational specialization to our empirical study. The aims of this study were to fill certain research gaps by exploring the associations among three key concepts: recreational specialization, environmental attitudes, and ecologically responsible behaviour of birdwatchers. The study is based on the results of a structured questionnaire survey conducted in Hong Kong, China. The remainder of this paper includes a brief history of birdwatching in Chinese society, an elaboration on the concept of recreational 
specialization and a description of the study design. The results of our structural equation modelling are then presented, and the implications of our findings are discussed in the concluding section.

\section{Development of birdwatching activities in China}

Birdwatching is one of the most popular nature-based activities, and it originated in the Western world (Shaw, Mangun, \& Lyons, 1985). Birdwatching was introduced to the East by birdwatchers from Western countries, and its popularity has rapidly increased in China over recent decades. Hong Kong was the first location in China where birdwatching developed, and an official society named the Hong Kong Birdwatching Society (HKBWS) was established in 1957 by a group of British Hong Kong residents, marking the start of birdwatching by the general public. In its early stages during colonial times, the majority of HKBWS members were non-local Westerners, notably British individuals (Cheung \& Cochrane, 2008). Presently, however, the local Chinese population accounts for the largest portion of HKBWS members (Cheung \& Cochrane, 2008).

Birdwatching is regarded as a type of nature-based tourism, and the environmental attitudes and behaviour of birdwatchers can directly impact natural destinations. Studies have indicated that most birdwatchers tend to visit natural destinations that present a likelihood of viewing endangered and endemic bird species. Research has shown that such birds are vulnerable to threats posed by human activities, such as inappropriate behaviour by visitors (Booth, Gaston, Evans, \& Armsworth, 2011). Therefore, an 
understanding of the environmental attitudes and behaviour of birdwatchers is needed to develop relevant guidelines and regulations to minimize inappropriate behaviour and negative impacts in bird conservation areas. However, few studies have investigated the environmental attitudes and behaviour of birdwatchers, and Steven et al. (2015) suggested based on their reviews that no such studies had been published in peerreviewed journals in the previous 25 years. Thus, research into this important research topic is scarce. This paper offers the first such study to be conducted in a Chinese context.

The recent development of digital technology has given rise to a new category of birdwatcher, wherein individual are often equipped with cameras with super telephoto lenses and electronic bird-calling devices (Sekercioglu, 2002). This new group of birdwatchers may not have an extensive knowledge of bird ecology and may not exhibit the environmentally friendly behaviour of traditional birdwatchers (Cheung, 2013). Moreover, their purposes for visiting birdwatching destinations may differ from those of traditional birdwatchers in that they aim to take beautiful wildlife photos rather than conserve and appreciate the wildlife (Harris \& Haskell, 2013). Therefore, this new group of birdwatchers may exhibit inappropriate behaviours, such as using electronic birdcalling devices and feeders to attract birds for photos. Such behaviours have been widely reported by magazines, newspapers and academic articles and may negatively impact wild bird populations (Buckley, 2004; Kronenberg, 2014; Sekercioglu, 2002). Wildlife watching and photography are regarded as a non-consumptive use of natural resources and should be encouraged because these activities can help generate tourism revenue, particularly in countries with rich biodiversity (Cheung \& Fok, 2014b; Cheung \& Jim, 
2014). However, inappropriate behaviour during these nature-based activities can be a major threat to wildlife. Proper management strategies for monitoring these behaviours need to be adopted to minimize negative visitor impacts to ecologically sensitive areas. Therefore, this study, which is aimed at understanding the environmental attitudes and behaviour of birdwatchers, is essential for conservation in nature-based destinations. This study enhances our understanding of the environmental attitudes and behaviour of birdwatchers and the effects of specialization on these attitudes and behaviour. The important findings of this study can be used as a reference for formulating proper visitor management strategies to eliminate or reduce inappropriate behaviour of visitors.

\section{Recreational specialization framework}

The term 'recreational specialization' was first defined by Bryan as 'a continuum of behaviour from the general to the particular, reflected by equipment and skills used in the sport and activity setting preferences' in a study of fishermen with different levels of specialization (Bryan, 1977, p.174). Recreational specialization develops through a series of stages of increasing involvement over time (Backlund \& Kuentzel, 2013; Oh, Sorice, \& Ditton, 2010). Long-term participation in a leisure activity tends to increase an individual's specialization, which is reflected in their skill level, equipment choices, and proficiency. Many specialization researches have built upon the original work of Bryan (1977). McFarlane (1996) suggested that through engaging in birdwatching activities, participants progress through stages of development and change their attitudes, preferences and group affiliations over time. Bentz, Lopes, Calado, and Dearden (2016) suggested that specialized participants are considered more knowledgeable and skilled in 
their chosen activity. They are more committed to the activity in terms of time and economic investment in equipment. Generally, specialization researchers have focused on behaviour, attitudes and values (Scott \& Shafer, 2001). Therefore, many studies have characterized specialization by including measurements of behavioural and attitudinal variables (Kuentzel \& Heberlein, 1992; McFarlane, 1994, 1996; Scott, Ditton, Stoll, \& Eubanks, 2005). To incorporate behavioural and attitudinal indicators in the assessment of the specialization of recreationalists, behavioural indicators such as participation, past experience, and frequency of participation have been included. Other indicators such as commitment (time and economic), economic investments, and affiliations with relevant organizations have also been included to assess the devotion and attachment of recreationists (Scott et al., 2005). Scott and Shafer (2001) suggested that specialization should be understood as consisting of three dimensions: a focusing of behaviour (years of involvement, frequency of participation and equipment owned), the acquisition of skills and knowledge (e.g. ability to identify species, skill at navigating white-water rapids), and personal and behavioural commitment (memberships in clubs and equipment purchases). Therefore, they suggested that all three dimensions should be key indicators for assessing the specialization of recreationists (Scott et al., 2005).

In Bryan's (1977) research, fishermen were divided into the following four groups based on their degree of specialization: 'occasional fishermen', 'generalists', 'technique specialists', and 'technique-setting specialists'. The characteristics of these groups varied, and Bryan found that the most specialized people who engaged in fishing held similar attitudes and beliefs and engaged in similar behaviour. Subsequently, the concept of recreational specialization was extended to the classification of different recreational 
activities for groups such as hikers (Wöran \& Arnberger, 2012), boaters, divers (Anderson \& Loomis, 2011; Dearden, Bennett, \& Rollins, 2006; Thapa, Graefe, \& Meyer, 2006), hunters (Kuentzel \& Heberlein, 1992) and birders (Lee \& Scott, 2004; Needham, Scott, \& Vaske, 2013; Scott et al., 2005; Scott \& Lee, 2010).

The framework of recreational specialization has been adopted in several studies that measured birding specialization (Scott et al., 2005; Scott \& Lee, 2010), divers' specialization (Ong \& Musa, 2012) and specialization of other wildlife tourists (Dearden

et al., 2006). Additional variables such as knowledge of target species and involvement in conservation initiatives have been included in measuring the specialization of wildlife tourists or recreationists (Dearden et al., 2006).

\section{Specialization of birdwatchers}

Based on previous studies (McFarlane, 1994, 1996), 10 items are frequently used to test the specialization of birdwatchersand divided into four groups: "past experience", "personal commitment", "economic commitment" and "achievement". Among studies focusing on birdwatching specialization, some have explored the characteristics of different specialized groups, such as their demographics, motivations, and birdwatching destination preferences (Chen \& Chen, 2015; Eubanks, Stoll, \& Ditton, 2004). Ong and Musa (2012) and Dearden et al. (2006) confirmed that the specialization of divers increases their pro-environmental behaviour, attitudes and environmental awareness. However, little research has addressed the associations between the specialization of birdwatchers and their environmental attitudes and ecologically responsible behaviour. 
The few previous studies suggest that specialization level is significantly associated with conservation intention (Bryan, 1977; McFarlane, 1996). McFarlane (1996) reported that birders' specialization level was positively correlated with conservation. However, Hvenegaard (2002) suggested that specialization level was only positively correlated with conservation group membership and not correlated with actual or hypothetical donations to conservation. Thus, additional studies are needed to determine the influence of specialization on pro-environmental attitudes and ecologically responsible behaviour. Our study represents an attempt to reveal the impact of birding specialization on the proenvironmental attitudes and ecologically responsible behaviour of birdwatchers. Our findings are important because they confirm the associations between birding specialization and pro-environmental attitudes and ecologically responsible behaviour in China. This study may also provide significant theoretical and practical contributions to birdwatching tourism and avian community conservation, including the identification of predictors of ecologically responsible behaviour of birdwatchers and suggestions for strategies of visitor management at birdwatching destinations.

Although previous studies of other groups of nature-based recreationists confirmed that increase specialization leads to improved environmental attitudes and behaviour (McFarlane, 1996; Ong \& Musa, 2012; Thapa et al., 2006), there is limited evidence to support such phenomena among various types of nature-based recreationists. Other studies, in contrast, reported that more specialized participants did not differ from lessspecialized ones in term of their interaction with the environment and commitment to the rules of or support for conservation. To test the influences of specialization of birdwatchers on pro-environmental attitudes and ecologically responsible behaviour, we 
posed the following three research hypotheses and tested them using data obtained from Chinese birdwatchers:

$\mathrm{H}_{1}-$ Birdwatchers' specialization is a significant predictor of positive environmental attitude (PEA).

$\mathrm{H}_{2}-$ Birdwatchers' specialization is a significant predictor of ecologically responsible behaviour (ERB).

$\mathrm{H}_{3}-$ Birdwatchers' PEA is a significant predictor of ERB.

\section{Methods}

\section{Study sites}

Southern China is one of the most important birdwatching regions in Asia, with tens of millions of birds migrating through or overwintering in its extensive wetlands. There are 512 sites measuring a total of 119,348,603 hectares in mainland China that have been listed as Important Bird Areas (IBAs) by Birdlife International. More than 1,240 bird species, including 54 endemic species and 29 endangered species, can be found in mainland China. The wetlands in South China are important wintering sites for many endangered species, such as the black-faced spoonbill Platalea minor and the spoon-bill sandpiper Calidris pygmaea. IBAs are popular birdwatching sites, and high numbers of birdwatchers regularly visit these sites; therefore, the birdwatching sites of the IBA in Hong Kong namely the Mai Po Nature Reserve and the wetland of the Inner Deep Bay were selected for the on-site questionnaire survey of birdwatchers. 
The extensive wetlands in north-western Hong Kong attract tens of thousands of waterbirds every winter. An area of more than 1500 hectares in north-western Hong Kong was designated a Ramsar Site (wetland of importance) in 1995 and has become a popular birdwatching destination for local and international birdwatchers. The extensive subtropical forests of Hong Kong also provide important habitat for woodland birds and also popular birdwatching sites. To include birdwatchers from two different birdwatching habitats, we conducted questionnaire surveys at popular wetland and woodland birdwatching destinations, specifically, the Mai Po Nature Reserve, the Tai Po Kau Nature Reserve, the Long Valley Wetland and the wetland of the Inner Deep Bay. These selected survey sites are the most popular traditional birdwatching locations in Hong Kong. They are easily accessible by public transport and attract both novice and expert birdwatchers.

\section{Development of the research instrument}

The data for addressing the research hypotheses were collected via a structured questionnaire survey. The questionnaire was divided into four sections to measure the respondents' pro-environmental attitudes, ecologically responsible behaviour, specialization and socio-economic characteristics. Six items related to environmental attitude were included in the first section. Three of these were items measuring negative environmental attitudes and were included to minimize extreme responses or acquiescent bias, and the negative environmental attitudes were coded in reverse in the data analysis. The items included in this scale were based on studies by Cheung and Fok (2014b) and Tao, Eagles, and Smith (2004) and modified for testing the attitudes of the respondents 
towards wildlife conservation. We considered these modified items as more appropriate than the original ones for understanding the pro-environmental attitudes of birdwatchers because these individuals are regarded as serious nature-based recreationists and their attitudes towards wildlife and wildlife conservation are relevant to the purpose of our study.

Section two of the questionnaire was developed to measure the ecologically responsible behaviour of the birdwatchers. The items adopted in this section were based on the codes of conduct for birdwatching activities proposed by various birdwatching associations, including the HKBWS, the American Birding Association, and The Royal Society for the Protection of Birds. Four common codes, i.e., 'keep distant from the target bird', 'obey related laws and regulations', and 'intervene or report unethical behaviour', were adopted and used as the items to assess the birdwatchers' ecologically responsible behaviour in the survey. These common codes of conduct were then converted to question items to test the ecologically responsible behaviour of the birdwatchers. Although previous studies have used a different set of items to measure the proenvironmental behaviour of other nature-based recreationists (Cheung \& Fok, 2014a; Lee \& Jan, 2015), we considered the questions that were used in these previous studies to be too overly generic and potentially inappropriate measuring the ecologically responsible behaviour of birdwatchers. Therefore, we designed the behavioural items based on the codes of conduct of birdwatching associations with the goal of maximizing the accuracy and validity of our study.

The items for measuring the birdwatchers' specializations were developed based on current recreational specialization frameworks. To address behaviour and attitude, 
eight items adapted from McFarlane (1994) were included in section three of the questionnaire and assigned to three dimensions, i.e., past experience, centrality-tolifestyle, and economic commitment, to offer a holistic measurement of the birdwatchers' specialization. A five-point Likert scale ranging from 'strongly agree' (score 5) to 'strongly disagree' (score 1) was used. The demographic variables included gender, age, education level, occupation and salary level. The questions were used to create profiles of the respondents.

\section{Survey sampling and data analysis}

The on-site questionnaire surveys were administered to participating birdwatchers at four of the most popular birdwatching locations in Hong Kong as described above. The surveys were administered on Saturdays and Sundays during the birdwatching season from September 2014 to March 2015. Birdwatchers were asked to complete the questionnaire, and six university students conducted the interviews. Upon request, the assistants provided explanations to the interviewees. Convenience sampling was adopted at the survey sites, and all of the birdwatchers that the interviewers met in the survey sites were approached and selected for the questionnaire survey. The participants required an average of 10 minutes to complete the questionnaire, and each respondent received a small gift after completing the survey.

The collected data were analysed using SPSS 21.0 for Windows to calculate Cronbach's alpha and descriptive statistics. The Cronbach's alpha scores for the latent variables of pro-environmental attitude (PEA), pro-environmental behaviour (PEB) and 
specialization (SPEC) were $0.757,0.704$, and 0.885 , respectively. All of the scores exceeded the threshold of 0.70 , indicating that the instrument had good internal consistency (Peterson, 1994). The proposed model (Figure 1) was examined by using structural equation modelling (SEM) in AMOS 21 to test both the theoretical relationships within the model and the overall fit of the model with the questionnaire data. All of the parameters were estimated using maximum likelihood estimation. The structural model examined the hypotheses using path analysis.

\section{Results}

\section{Respondent profiles}

In total, 417 birdwatchers were approached, and 387 (more than 92\%) successfully completed the questionnaires (Table 1). More than $81 \%$ of the respondents were male. More than $75 \%$ of the respondents were above the age of 35 , and over $26 \%$ of the respondents were between the ages of 45 and 54. Less than $8.5 \%$ of the birdwatchers were below the age of 24 . The majority of respondents $(70.3 \%)$ had a post-secondary education or higher, whereas less than $10 \%$ had a secondary education or below. More than $65 \%$ of the respondents earned a monthly salary of less than HK $\$ 20,000$ (US\$2,564), whereas $21.1 \%$ earned more than HK $\$ 30,000$ (US\$3,846) the median monthly salary is Hong Kong is HK\$13,000 (US $\$ 1,667$ ) (The Census and Statistics Department, 2013). Regarding occupational status, approximately $70 \%$ were actively working, and more than $20 \%$ were retired. 


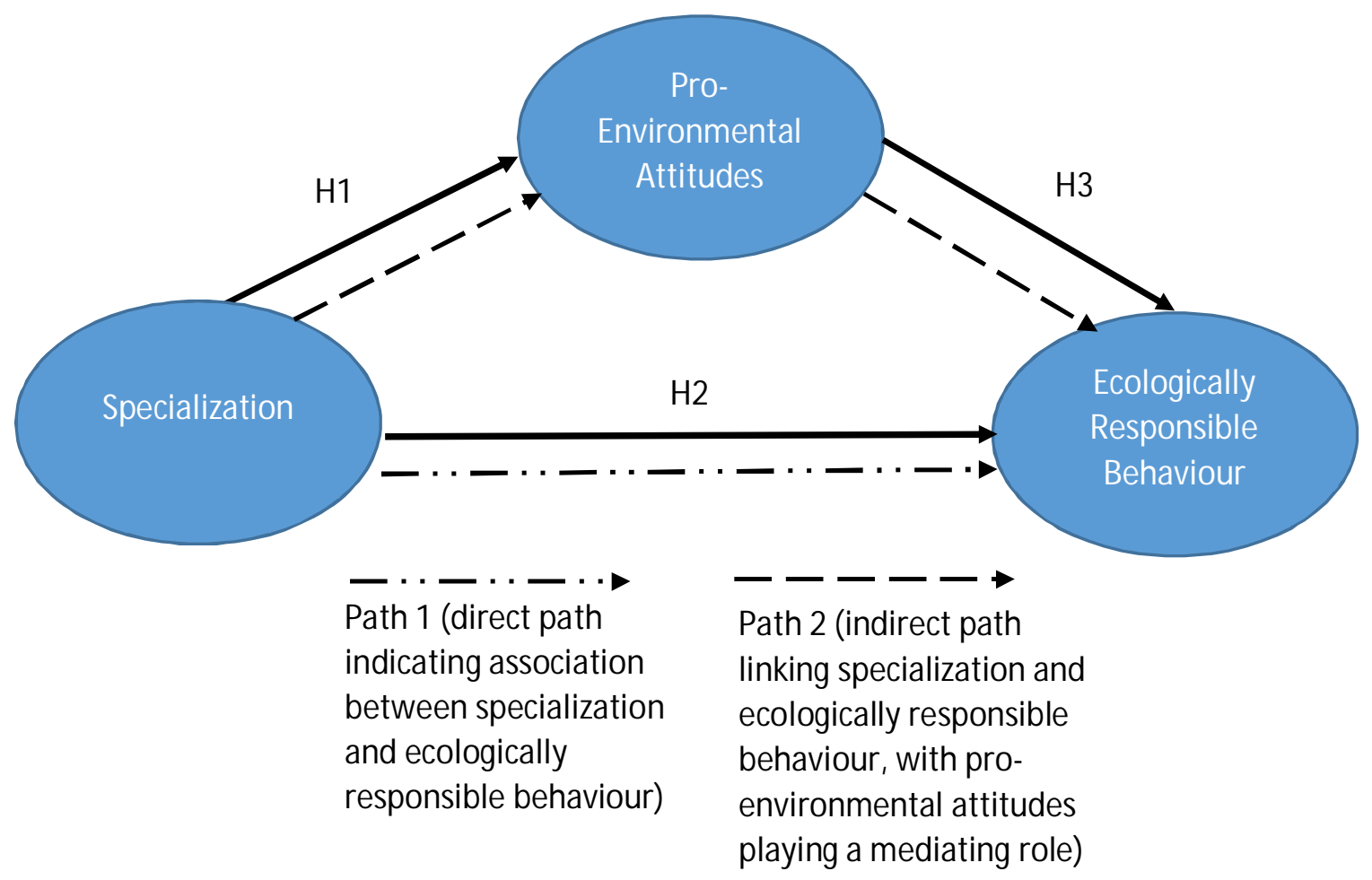

Figure 1: Proposed theoretical model for this study

\section{Descriptive statistics}

The descriptive results of the four sets of variables are shown in Table 2. The mean score for the eight items concerning birdwatchers' specialization (SPEC) ranged from 2.08-3.81 out of 5 (Table 2). Item S4, 'Birdwatching is my favourite outdoor activity compared with others', scored the highest (3.81), suggesting that participants are committed to birdwatching activities, and it was followed by Item S1, 'How long have you been paticipating in birdwatching activities?', which scored 3.48, indicating that the average number of years of experience for Hong Kong birdwatchers is at least 2. Item S3, 'How much time you usually spend on your birdwatching trips?', scored the lowest (2.08), indicating that Hong Kong birdwatchers spend approximately 2 hours per trip, 
which in part reflects the short distances between popular birdwatching sites and the city. All of the items were selected as a composite variable for further analysis. The composite reliability was 0.885 , thus indicating high reliability.

Six items were used to test the pro-environmental attitude of the birdwatchers, and the following three negative items were included to minimize and reduce extreme response or acquiescent bias: Item A1, 'We could make use of wildlife resources to improve our quality of life'; Item A3, 'For the sake of economic benefit or health, we could hunt and eat some wild animals'; and Item A5, 'Wildlife rights are less important than human rights'. The respondents generally indicated agreement with the proenvironmental attitude items (PEA), and the scores ranged from 3.07 to 4.25 , with the mean scores of all of the six items exceeding 3 (Table 2). Item A2, 'No activity that harm wildlife is allowed, no matter how much we can benefit from it', scored the highest (4.24), followed by Item A4, 'Humans should not hunt or eat wild animals for our interests' (4.13). These scores suggest that the participants generally agreed that the rights of animals and human are of equal importance and that humans should not harm wildlife for their own benefit. The factor loading for Item A1 was below 0.4; therefore, this item was deleted. The reliability of the composite variable 'pro-environmental attitude' was 0.757 after deleting Item A1. 
Table 1. Respondents' demographic characteristics

\begin{tabular}{llr}
\hline Socioeconomic variables & \multicolumn{2}{c}{$\begin{array}{c}\text { Respondents } \\
(\%)\end{array}$} \\
\hline Gender & Male & 81.9 \\
& Female & 18.1 \\
\hline Age Range & Below 15 & 3.6 \\
& $15-24$ & 4.7 \\
& $25-34$ & 16.5 \\
& $35-44$ & 20.2 \\
& $45-54$ & 26.4 \\
& $55-64$ & 20.2 \\
& 65 or above & 8.5 \\
\hline Education Level & Primary or below & 3.9 \\
& Lower secondary & 5.4 \\
& Upper secondary & 20.4 \\
& Post & 59.2 \\
& secondary/undergraduate & 11.1 \\
\hline Palary Range $($ HK\$) & Below 10,000 & 28.9 \\
& 10,001 - 20,000 & 36.4 \\
& 20,001 - 30,000 & 13.4 \\
& 30,001 - 40,000 & 12.1 \\
& Above 40,000 & 9.0 \\
\hline Occupational Status & Student & 5.5 \\
& Unemployed & 3.4 \\
& Employed & 70.6 \\
& Retired & 20.5 \\
\hline
\end{tabular}


Range Mean

S1 How long have you been participating in birdwatching activities?

S2 How many days did you spend birdwatching last year?

$1-5-3.48$

S3 How much time you usually spend on your birdwatching trips?

S4 Birdwatching is my favourite outdoor activities compared with others.

S5 Most of my outdoor recreational activity aims at watching birds.

S6 What is the cost of all your birdwatching equipment?

S7 How many species can you identify without help from a bird identification book?

S8 How professional do you think you are as a birdwatcher?

\section{Pro-environmental attitudes (PEA)}

A1 We could make use of wildlife resources to improve our quality of life. $\boldsymbol{R}^{*}$ A2 No activity that harms wildlife is allowed, no matter how much we can benefit from it.

A3 For the sake of economic benefit or health, we could hunt and eat some wild animals. $\boldsymbol{R}$

A4 Humans should not hunt or eat wild animals for our interests.

A5 Wildlife rights are less important than human rights. $\boldsymbol{R}$

A6 The rights of humans and wildlife are equally important.

\section{Ecologically responsible behaviour $(\mathrm{ERB})$}

B1 I would not make any changes to the distribution of vegetation in a habitat.*

B2 I will try to keep a certain distance from target birds and avoid disturbance.

B3 During birdwatching, I have obeyed all related regulations and laws.

B4 I would not intentionally interact with birds or attract them.*
$1-5$

$1-5$

$1-5$

1-5

1-5

1-5

$1-5$

$1-5$

3.48

3.73

2.08

3.81

3.38

3.35

2.39

2.5

1.192

1.294

0.57

0.878

0.72

1.045

1.095

1.52

0.65

0.67

0.61

1.405

1.107

3.852

1-5

3.07

1-5

4.25

1-5

$1-5$

\subsection{7}

4.13

3.72

4.07

4.326

1-5

4.53

1-5

1-5

1-5

$$
4.41
$$

4.5

4.64

1-5
0.66

0.885

B5 I will intervene if I observe bad or unethical behaviour which would harm birds.

* items have been excluded because the factor loadings were below 0.4

\# the values were computed after exclusion of the deleted items

$\boldsymbol{R}$ reversed coding 
The mean ecologically responsible behaviour (ERB) scores of the respondents were consistently high, ranging from 4.41 to 4.65 . Item B4, 'I would not intentionally interact with birds or attract them', had the highest mean score (4.64), followed by Item B1, 'I would not make any changes to the distribution of vegetation in a habitat' (4.53). These scores indicated that the birdwatchers strongly agreed that people should not cause disturbances to the avian community when they are watching birds. The least agreeable was Item B5, 'I will intervene if I observe bad or unethical behaviour which would harm birds' (3.55), suggesting that the majority of birdwatchers are not inclined to intervene when observing unethical behaviour. The composite reliability $(\mathrm{CR})$ of the variable 'ecologically responsible behaviour' was measured, and the CR of items B1 and B4 were lower than 0.4. Therefore, these two items were deleted, which increased the CR to 0.704 , a value sufficiently reliable for further data analysis.

\section{Structural relationships between key variables}

The measurement model specified how the latent variables should be assessed in terms of the observed variables, and the validity and reliability of the responses to the observed variables and the latent variables were represented. A confirmatory factor analysis (CFA) and SEM were used to test the conceptual model of the causal relationships between specialization and each of pro-environmental attitude and ecologically responsible behaviour. The confirmatory factor analysis indicated that the $\chi^{2}$ of the measurement model was 617.32, with 130 degrees of freedom $(d f)(p<0.05)$; therefore, the $\chi^{2} / d f$ value was less than 5.0, thus implying that the measurement model had an acceptable fit to the data (Fan, Thompson, \& Wang, 1999). Other measurement 
model fit indices were calculated to further verify model fitness. As a general rule, the root mean square error of approximation (RMSEA) should be lower than or close to 0.05 , the CFI should exceed 0.93, and the IFI should exceed 0.92 (Fan et al., 1999). Our model (Figure 2) achieved an RMSEA value of 0.06, a CFI of 0.92, and an IFI of 0.94, which are near the threshold values.

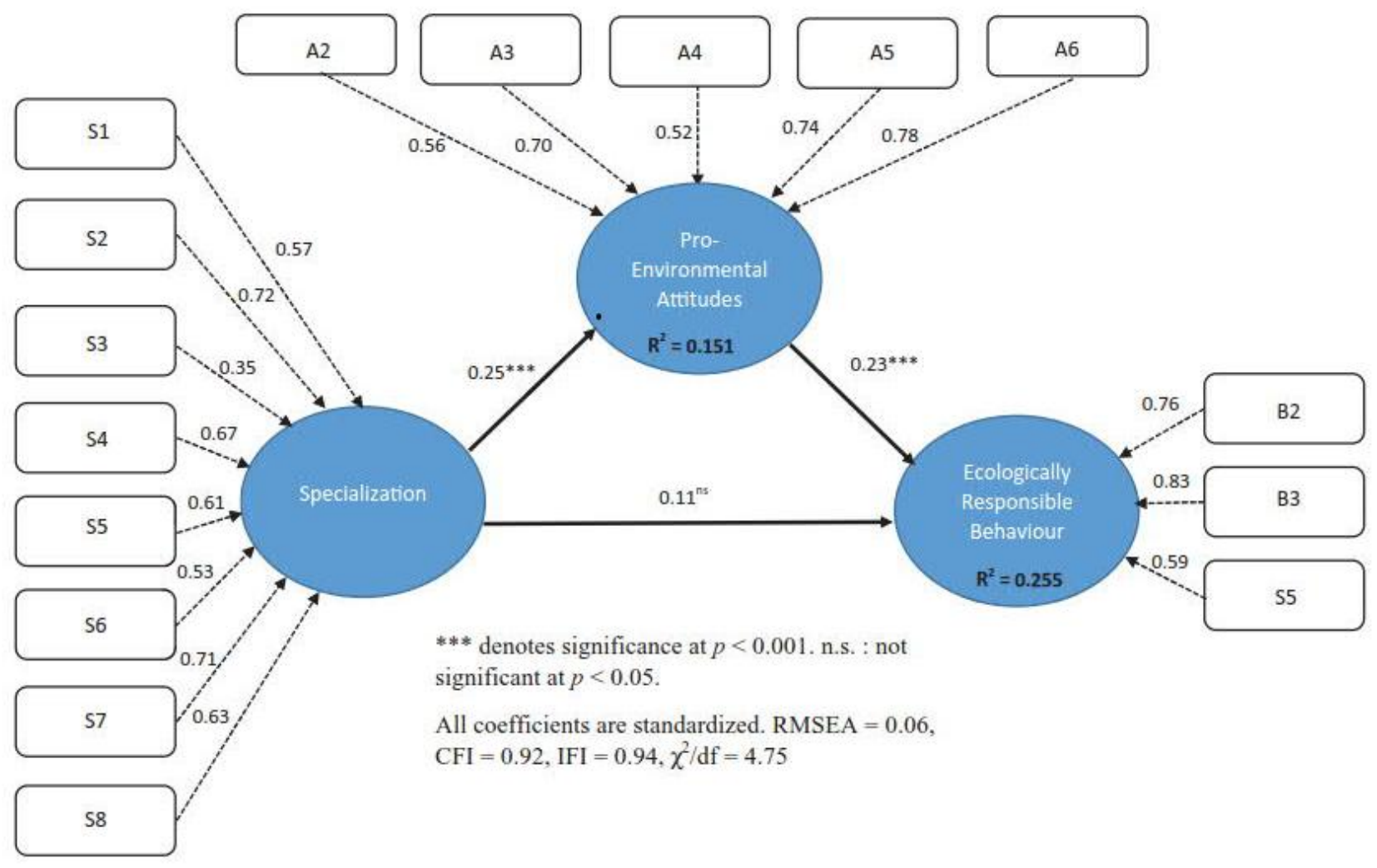

Figure 2. Structural model of birdwatchers' specialization, pro-environmental attitudes, and ecologically responsible behaviour.

Figure 2 presents the results of the structural modelling of the relationships among the variables. The path diagram shows the linear relationships among the SPEC, PEA, and ERB scores. SPEC was positively correlated with PEA, indicating that the specialization of Chinese birdwatchers predicts their pro-environmental attitudes; therefore, $\mathrm{H} 1$ is supported. However, the results indicate an insignificant association between SPEC and ERB; therefore, $\mathrm{H} 2$ is not supported. A significant association between PEA and ERB was 
observed, indicating that PEA is an important predictor of ERB; therefore, $\mathrm{H} 3$ is supported. The results also suggest that SPEC indirectly affects ERB by mediating PEA (Figure 3). In addition, the squared multiple correlation (equivalent to $R^{2}$ ) was 0.151 for PEA, suggesting that $15.1 \%$ of the variance in PEA can be attributed to SPEC. The squared multiple correlation for ERB was 0.255 , indicating that $25.5 \%$ of the variance in ERB can be attributed to SPEC and PEA.

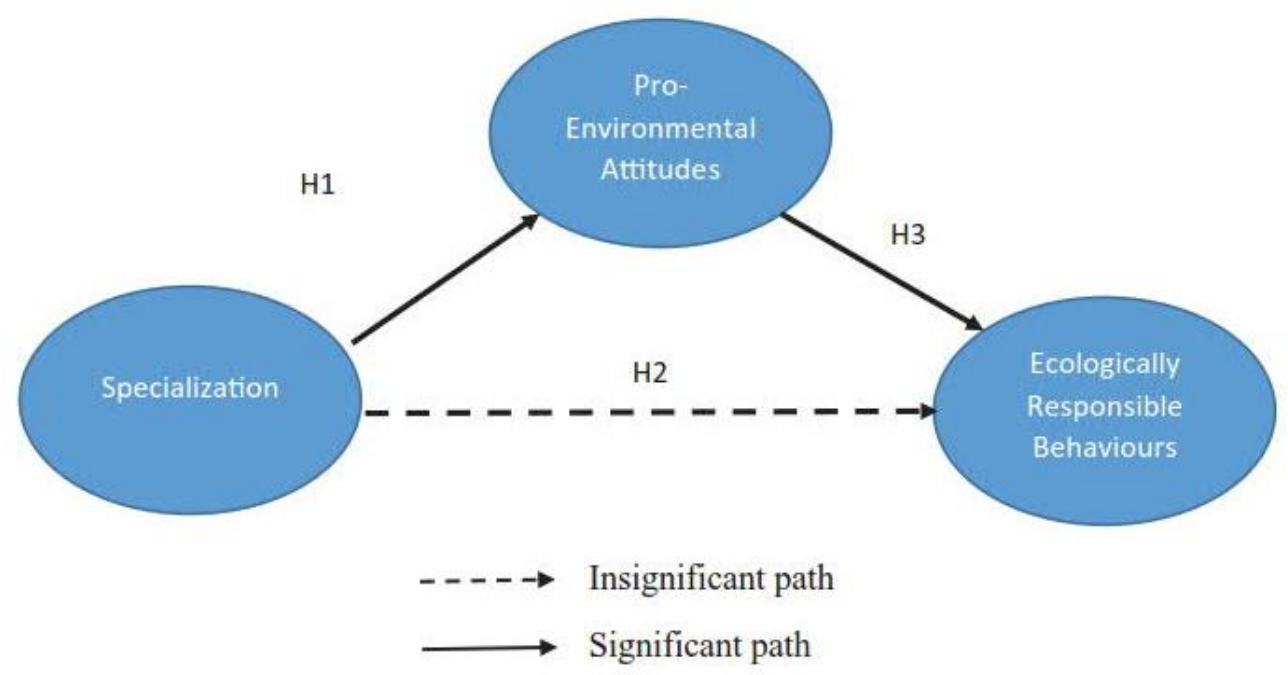

Figure 3. Observed relationships among birdwatchers' specialization, positive environmental attitudes, and ecologically responsible behaviour.

\section{Discussion}

The reported path estimates from the current study consistently support hypotheses $\mathrm{H} 1$ and $\mathrm{H} 3$ but not $\mathrm{H} 2$. The findings indicate that Chinese birdwatcher specialization significantly predicts pro-environmental attitudes but not ecologically responsible behaviour, which indicates that more specialized Chinese birdwatchers do not necessarily adopt ecologically responsible behaviour while birdwatching. These findings are consistent with those of Camp and Fraser (2012), who reported that the experience 
level of divers did not correlate significantly with their pro-environmental behaviour. However, our findings challenge the results of Bryan (1977), who suggested that more specialized recreationists shift their focus from consumption to conservation. Moreover, both Hvenegaard (2002) and Boxall and McFarlane (1993) reported that birdwatchers with higher specialization levels showed a greater willingness to pay for annual conservation or wildlife association memberships compared with birdwatchers with lower levels of specialization.. This discrepancy between the present study and previous ones may be related to study differences in the items used to measure pro-environmental behaviour. In present study, the question items measured on-site behaviour of birdwatchers. Cultural differences between Chinese birdwatchers and those of other countries might be another might be another factor contributing to the discrepancy.

The suggested birdwatching behaviour listed in the published codes of conduct of various birdwatching associations were converted into items in our survey to directly measure the ecologically responsible behaviour of birdwatchers. We performed this conversion because we believed that these items to be more relevant than the items used in previous studies and likely to garner greater consensus from birdwatchers at various levels of specialization. Our results suggest that all levels of birdwatchers indicated general agreement with most of the suggested birdwatching behaviour. This finding is supported by the results of Weston et al. (2015), who found that birdwatchers strongly believe that they should take appropriate measures to minimize their disturbance to birds. However, the results of our study indicate that the respondents would be hesitant to intervene if they observed others exhibiting unethical birdwatching behaviour. This hesitance may reflect the general discouragement in Chinese society of confrontation 
with people behaving poorly. Most Chinese individuals would prefer not to report misconduct or injustice to authorities such as park management agencies to avoid potential rebukes or punishment themselves (Chiu, 1991). Such individuals may fear that the people they report on may insult them for reporting.

Although our results suggested that an association did not occur between the specialization and ecologically responsible behaviour of Chinese birdwatchers, a significant positive association was observed between specialization (SPEC) and proenvironmental attitude (PEA). The lack of association between specialization and ecologically responsible behaviour may be due to some birdwatchers who engage in unethical behaviour and are focus on adding bird species to their lists. Their interest in listing prevents them from practising ecologically responsible behaviour. However, the finding of a positive association between specialization and environmental attitude generally supports previous research findings, in which positive relationships were demonstrated between recreational specialization and environmental concerns (Bryan, 1977; Thapa et al., 2006). Birdwatchers typically consider themselves to be environmentally aware and sensitive; however, research results have not positively demonstrated whether such traits manifest as consistent behavioural traits (Jones \& Buckley, 2001; Weston et al., 2015). The path analysis in this study revealed a positive association between the pro-environmental attitudes and ecologically responsible behaviour of Chinese birdwatchers. This association is supported by social psychological theories that suggest behaviour is likely to be influenced by attitudes (Kraus, 1995; Weston et al., 2015). 
Our results indicated that PEA predicted PEB, which completes Path 2 (Figure 1) by linking specialization (SPEC) and ecologically responsible behaviour (ERB). Here, PEA played a mediating role and was correlated with the other two variables, which would otherwise have no connection. The key findings of this research are that the specialization of Chinese birdwatchers can influence PEA and that shaping these attitudes influences pro-environmental birdwatching behaviour. These results represent indirect pathways through which pro-environmental attitudes influence ecologically responsible behaviour.

\section{Conclusion}

This study demonstrated that birdwatchers' specialization is generally a reliable predictor of pro-environmental attitudes and ecologically responsible behaviour, which has not been clearly demonstrated in previous studies particularly in a Chinese context. The findings of this study validate the theoretical framework that describes the associations between birdwatchers' specialization and pro-environmental attitudes and ecologically responsible behaviour. They also offer theoretical and practical contributions to the field of sustainable tourism, particularly nature-based tourism. These findings are of relevance to managers of protected areas, who can develop appropriate approaches for visitor management practices in bird sanctuaries. Specific indicators of recreational specialization, such as the equipment birdwatchers use for field observations and the years of birdwatching experience, can be used to predict the likely pro-environmental attitudes and ecologically responsible behaviour patterns of various groups of visitors. Such information can help protected areas managers estimate the likelihood of 
ecologically irresponsible behaviour at birdwatching sites and devise effective strategies for managing visitors and preventing unsustainable practices.

Due to time limitations, we were only able to collect data at birdwatching sites in Hong Kong although some of our respondents were from mainland China and Taiwan. Therefore, our data are not representative of Chinese birdwatchers from mainland China and Taiwan. Hong Kong Chinese birdwatchers may exhibit different pro-environmental attitudes and ecologically responsible behaviour from their counterparts from mainland China and Taiwan due to the longer development time of the birdwatching activities in Hong Kong. They are also likely to be more specialized than birdwatchers from mainland China and Taiwan. Therefore, further data from mainland Chinese and Taiwanese birdwatchers are essential to draw conclusions regarding the specialization, environmental attitude and behaviour of Chinese birdwatchers. In addition, exploring alternative determinants, e.g. place attachment (Cheng, C. Wu, \& Huang, 2013; Ramkissoon, Smith, \& Weiler, 2013), for predicting ecologically responsible behaviour of birdwatchers may benefit birdwatching tourism research in the future.

The international birding market is growing rapidly, and reliable predictions of birdwatcher behaviour can potentially allow managers of birdwatching sites to formulate appropriate visitor management strategies for site management. In addition, the increase in the birding market might provide economic and environmental benefits to host destinations. For countries with a diversity of avian resources, an understanding of the likelihood of ecologically responsible behaviour among their potential nature-based tourists is needed. Such an understanding is crucial for ensuring that their visits generate tourism revenue without negative impacts on valuable wildlife tourism resources (Giglio 
et al., 2015). This empirical study clearly demonstrates that the study of birdwatchers' specialization can be used to understand pro-environmental attitudes and ecologically responsible behaviour, which can provide important information for managing humanwildlife interactions in protected areas worldwide.

\section{References}

Anderson, L. E., \& Loomis, D. K. (2011). SCUBA Diver Specialization and Behavior Norms at Coral Reefs. Coastal Management, 39(5), 478-491. doi: $10.1080 / 08920753.2011 .598813$

Backlund, E. A., \& Kuentzel, W. F. (2013). Beyond Progression in Specialization Research: Leisure Capital and Participation Change. Leisure Sciences, 35(3), 293299. doi: $10.1080 / 01490400.2013 .780543$

Bentz, J., Lopes, F., Calado, H., \& Dearden, P. (2016). Managing marine wildlife tourism activities: Analysis of motivations and specialization levels of divers and whale watchers. Tourism Management Perspectives, 18, 74-83. doi: http://dx.doi.org/10.1016/j.tmp.2016.01.004

Booth, J. E., Gaston, K. J., Evans, K. L., \& Armsworth, P. R. (2011). The value of species rarity in biodiversity recreation: A birdwatching example. Biological Conservation, 144(11), 2728-2732. 
Boxall, P. C., \& McFarlane, B. L. (1993). Human Dimensions of Christmas Bird Counts: Implications for Nonconsumptive Wildlife Recreation Programs. Wildlife Society Bulletin (1973-2006), 21(4), 390-396. doi: 10.2307/3783409

Bryan, H. (1977). Leisure value systems and recreational specialization: The case of trout fishermen. Journal of Leisure Research, 9(3), 174-187.

Buckley, R. (2004). Ecotourism policy and planning. Journal of Sustainable Tourism, 12(1), 86-87.

Burger, J., Jeitner, C., Clark, K., \& Niles, L. J. (2004). The effect of human activities on migrant shorebirds: successful adaptive management. Environmental Conservation, 31(04), 283-288.

Camp, E., \& Fraser, D. (2012). Influence of conservation education dive briefings as a management tool on the timing and nature of recreational SCUBA diving impacts on coral reefs. Ocean \& Coastal Management, 61, 30-37. doi: http://dx.doi.org/10.1016/j.ocecoaman.2012.02.002

Chen, L. J., \& Chen, W. P. (2015). Push-pull factors in international birders' travel. Tourism Management, 48, 416-425. doi: http://dx.doi.org/10.1016/j.tourman.2014.12.011

Cheng, T.-M., C. Wu, H., \& Huang, L.-M. (2013). The influence of place attachment on the relationship between destination attractiveness and environmentally responsible behavior for island tourism in Penghu, Taiwan. Journal of Sustainable Tourism, 21(8), 1166-1187. doi: 10.1080/09669582.2012.750329 
Cheng, Y., Wang, J., He, X., \& Ma, Z. (2013). Present status and development of the birdwatching in mainland China. Journal of East China Normal University (Natural Science), 2, 011.

Cheung, L. T. O. (2013). Improving visitor management approaches for the changing preferences and behaviours of country park visitors in Hong Kong. Natural Resources Forum, 37(4), 231-241. doi: 10.1111/1477-8947.12025

Cheung, L. T. O., \& Fok, L. (2014a). Assessing the role of ecotourism training in changing participants' pro-environmental knowledge, attitudes and behaviours. Asia Pacific Journal of Tourism Research, 19(6), 645-661. doi: $10.1080 / 10941665.2013 .797003$

Cheung, L. T. O., \& Fok, L. (2014b). The motivations and environmental attitudes of nature-based visitors to protected areas in Hong Kong. International Journal of Sustainable Development \& World Ecology, 21(1), 28-38. doi: $10.1080 / 13504509.2013 .832711$

Cheung, L. T. O., Fok, L., Tsang, E. P. K., Fang, W., \& Tsang, H. Y. (2015). Understanding residents' environmental knowledge in a metropolitan city of Hong Kong, China. Environmental Education Research, 21(4), 507-524.

Cheung, L. T. O., \& Jim, C. (2014). Expectations and willingness-to-pay for ecotourism services in Hong Kong's conservation areas. International Journal of Sustainable Development \& World Ecology, 21(2), 149-159. 
Cheung, S. C. H., \& Cochrane, J. (2008). Wetland tourism in Hong Kong: from birdwatcher to mass ecotourist. London: Elsevier Science.

Chiu, C.-Y. (1991). Responses to Injustice in Popular Chinese Sayings and among Hong Kong Chinese Students. The Journal of Social Psychology, 131(5), 655-665. doi: $\underline{10.1080 / 00224545.1991 .9924649}$

Dearden, P., Bennett, M., \& Rollins, R. (2006). Implications for coral reef conservation of diver specialization. Environmental Conservation, 33(04), 353-363. doi: doi:10.1017/S0376892906003419

Dearden, P., Bennett, M., \& Rollins, R. (2007). Perceptions of Diving Impacts and Implications for Reef Conservation. Coastal Management, 35(2-3), 305-317. doi: $\underline{10.1080 / 08920750601169584}$

Douglas, M. J. W. (1971). Behaviour responses of red deer and chamois to cessation of hunting. New Zealand Journal of Science, 14(3), 507-518.

Eubanks, T. L., Stoll, J. R., \& Ditton, R. B. (2004). Understanding the Diversity of Eight Birder Sub-populations: Socio-demographic Characteristics, Motivations, Expenditures and Net Benefits. Journal of Ecotourism, 3(3), 151-172. doi: $\underline{10.1080 / 14664200508668430}$

Fan, X., Thompson, B., \& Wang, L. (1999). Effects of sample size, estimation methods, and model specification on structural equation modeling fit indexes. Structural Equation Modeling: A Multidisciplinary Journal, 6(1), 56-83. doi: $\underline{10.1080 / 10705519909540119}$ 
Giglio, V., Luiz, O., \& Schiavetti, A. (2015). Recreational Diver Behavior and Contacts with Benthic Organisms in the Abrolhos National Marine Park, Brazil. Environmental Management, 1-12. doi: 10.1007/s00267-015-0628-4

Harris, J. B. C., \& Haskell, D. G. (2013). Simulated Birdwatchers' Playback Affects the Behavior of Two Tropical Birds. PLoS ONE, 8(10), e77902. doi: $\underline{10.1371 / \text { journal.pone.0077902 }}$

Hill, S. G., Cable, T. T., \& Scott, D. (2010). Wildlife-based recreation as economic windfall: a rhetorical analysis of public discourse on birding. Applied Environmental Education and Communication, 9(4), 224-232.

Hvenegaard, G. T. (2002). Birder Specialization Differences in Conservation Involvement, Demographics, and Motivations. Human Dimensions of Wildlife, 7(1), 21-36. doi: 10.1080/108712002753574765

Hvenegaard, G. T., Butler, J. R., \& Krystofiak, D. K. (1989). Economic Values of Bird Watching at Point Pelee National Park, Canada. Wildlife Society Bulletin, 17(4), 526-531. doi: $10.2307 / 3782724$

Jones, D. N., \& Buckley, R. (2001). Birdwatching tourism in Australia Wildlife Tourism Research Report Series: No. 10. Australia: CRC Sutainable Tourism.

Knight, R. L., \& Temple, S. A. (1986). Why does intensity of avian nest defense increase during the nesting cycle? The Auk, 318-327. 
Kraus, S. J. (1995). Attitudes and the Prediction of Behavior: A Meta-Analysis of the Empirical Literature. Personality and Social Psychology Bulletin, 21(1), 58-75. doi: $10.1177 / 0146167295211007$

Kronenberg, J. (2014). Environmental impacts of the use of ecosystem services: Case study of birdwatching. Environmental Management, 54(3), 617-630. doi: $10.1007 / \mathrm{s} 00267-014-0317-8$

Kuentzel, W. F., \& Heberlein, T. A. (1992). Does specialization affect behavioral choices and quality judgments among hunters? Leisure Sciences, 14(3), 211-226. doi: $\underline{10.1080 / 01490409209513169}$

Lee, J.-H., \& Scott, D. (2004). Measuring Birding Specialization: A Confirmatory Factor Analysis. Leisure Sciences, 26(3), 245-260. doi: 10.1080/01490400490461387

Lee, T. H., \& Jan, F.-H. (2015). The Effects of Recreation Experience, Environmental Attitude, and Biospheric Value on the Environmentally Responsible Behavior of Nature-Based Tourists. Environmental management, 56(1), 193-208.

Li, L., En, W., \& Ling, S.-j. (2009). Analysis of Beijing bird-watching tourists behavior characteristics. Journal of Harbin University of Commerce (Social Science Edition), 1, 032.

Ma, Z., Cheng, Y., Wang, J., \& Fu, X. (2013). The rapid development of birdwatching in mainland China: a new force for bird study and conservation. Bird conservation international, 23(02), 259-269. 
Maple, L. C., Eagles, P. F. J., \& Rolfe, H. (2010). Birdwatchers' specialisation characteristics and national park tourism planning. Journal of Ecotourism, 9(3), 219-238. doi: 10.1080/14724040903370213

Marzluff, J. M. (1988). Do Pinyon Jays alter nest placement based on prior experience? Animal Behaviour, 36(1), 1-10.

McFarlane, B. L. (1994). Specialization and Motivations of Birdwatchers. Wildlife Society Bulletin, 22(3), 361-370. doi: 10.2307/3783377

McFarlane, B. L. (1996). Socialization influences of specialization among birdwatchers. Human Dimensions of Wildlife, 1(1), 35-50. doi: 10.1080/10871209609359050

Needham, M. D., Scott, D., \& Vaske, J. J. (2013). Recreation Specialization and Related Concepts in Leisure Research. Leisure Sciences, 35(3), 199-202. doi: $\underline{10.1080 / 01490400.2013 .780457}$

Oh, C.-O., Sorice, M. G., \& Ditton, R. B. (2010). Exploring Progression along the $\underline{\text { Recreation Specialization Continuum Using a Latent Growth Approach. Leisure }}$ Sciences, 33(1), 15-31. doi: 10.1080/01490400.2011.533104

Ong, T. F., \& Musa, G. (2012). Examining the influences of experience, personality and attitude on SCUBA divers' underwater behaviour: A structural equation model. Tourism Management, 33(6), 1521-1534. doi: http://dx.doi.org/10.1016/j.tourman.2012.02.007 
Peterson, R. A. (1994). A meta-analysis of Cronbach's coefficient alpha. Journal of consumer research, 21(2), 381-391.

Ramkissoon, H., Smith, L. D. G., \& Weiler, B. (2013). Relationships between place attachment, place satisfaction and pro-environmental behaviour in an Australian national park. Journal of Sustainable Tourism, 21(3), 434-457. doi:

$10.1080 / 09669582.2012 .708042$

Scott, D., Ditton, R. B., Stoll, J. R., \& Eubanks, T. L. (2005). Measuring Specialization among Birders: Utility of a Self-Classification Measure. Human Dimensions of Wildlife, 10(1), 53-74. doi: 10.1080/10871200590904888

Scott, D., \& Lee, J.-H. (2010). Progression, Stability, or Decline? Sociological Mechanisms Underlying Change in Specialization Among Birdwatchers. Leisure Sciences, 32(2), 180-194. doi: 10.1080/01490400903547203

Scott, D., \& Shafer, C. S. (2001). Recreational specialization: A critical look at the construct. Journal of Leisure Research, 33(3), 319-343.

Scott, D., \& Thigpen, J. (2003). Understanding the Birder as Tourist: Segmenting Visitors to the Texas Hummer /Bird Celebration. Human Dimensions of Wildlife, 8(3), 199-218. doi: 10.1080/10871200304311

Sekercioglu, C. H. (2002). Impacts of birdwatching on human and avian communities. Environmental Conservation, 29(03), 282-289. doi: doi:10.1017/S0376892902000206 
Shaw, W. W., Mangun, W. R., \& Lyons, J. R. (1985). Residential enjoyment of wildlife resources by Americans. Leisure Sciences, 7(3), 361-375.

Steven, R., Morrison, C., \& Castley, J. G. (2015). Birdwatching and avitourism: a global review of research into its participant markets, distribution and impacts, highlighting future research priorities to inform sustainable avitourism management. Journal of Sustainable Tourism, 23(8-9), 1257-1276. doi: $\underline{10.1080 / 09669582.2014 .924955}$

Tao, C. H., Eagles, P. F., \& Smith, S. L. J. (2004). Profiling Taiwanese ecotourists using a self-definition approach. Journal of Sustainable Tourism, 12(2), 149-168.

Thapa, B., Graefe, A. R., \& Meyer, L. A. (2006). Specialization and marine based environmental behaviors among SCUBA divers. Journal of Leisure Research, 38(4), 601-615.

The Census and Statistics Department. (2013). Quarterly Report on General Household Survey. Retrieved from

Vicente-Molina, M. A., Fernández-Sáinz, A., \& Izagirre-Olaizola, J. (2013). Environmental knowledge and other variables affecting pro-environmental behaviour: comparison of university students from emerging and advanced countries. Journal of Cleaner Production, 61, 130-138. doi: http://dx.doi.org/10.1016/j.jclepro.2013.05.015 
Weston, M. A., Guay, P.-J., McLeod, E. M., \& Miller, K. K. (2015). Do Birdwatchers Care about Bird Disturbance? Anthrozoös, 28(2), 305-317. doi: $10.1080 / 08927936.2015 .11435404$

Wöran, B., \& Arnberger, A. (2012). Exploring Relationships Between Recreation Specialization, Restorative Environments and Mountain Hikers' Flow Experience.

Leisure Sciences, 34(2), 95-114. doi: 10.1080/01490400.2012.652502 